\title{
The Impact of Gas Flaring in Nigeria
}

\author{
Omoniyi Omotayo Adewale, Ubale Mustapha \\ Department of Petroleum Engineering, Abubakar Tafawa Balewa University, Bauchi State, Nigeria
}

\section{Email address:}

omotosimple4u@gmail.com (O. O. Adewale)

\section{To cite this article:}

Omoniyi Omotayo Adewale, Ubale Mustapha. The Impact of Gas Flaring in Nigeria. International Journal of Science, Technology and Society. Vol. 3, No. 2, 2015, pp. 40-50. doi: 10.11648/j.ijsts.20150302.12

\begin{abstract}
Nowadays, petroleum hydrocarbons are widely used as fuels for energy and power generation. However, the production of such fuels complements the flaring of gas in Nigeria. Therefore, this research investigates the various ways in which gas flaring affects the populace of the Niger Delta region of Nigeria, which is the bedrock of Nigeria's current oil and gas resources. Also, the research work attempts to offer solutions on how a feasible and reliable gas industry and market can be developed in Nigeria. The research makes use of literatures relevant to gas flaring, and a questionnaire was distributed to three states namely; AkwaI bom, Rivers and Bayelsa. To figure out the environmental, social and economic impacts of gas flaring in those areas, a thorough research led to findings that gas flaring causes health problems for the people, a damaged and unsustainable environment, as well as socio-economic problems. Furthermore, the research shows recommendations for solutions on the development of a viable gas industry, and also economic prospects in relation to the development of a proper gas plan in Nigeria.
\end{abstract}

Keywords: Petroleum Hydrocarbons, Oil and Gas, Gas Flaring, Environment, Income, Health

\section{Introduction}

Nigeria is a nation highly endowed with natural resources such as mineral deposits, natural gases and petroleum. These have been a blessing in some instances, and in others it is nothing but a continuous source of pain and sorrow to the countries that are located where these natural resources may be found. Some of these natural sources are a windfall for these nations, while others struggle to deal with social afflictions such as pollution, disease and environmental consequences that come with the resources (Human Development Report 2011) ${ }^{13}$.

The extensive inventory of natural resources, consisting of natural gas and petroleum, in the nation of Nigeria is situated in a region referred to as the Niger Delta. With access to the Atlantic Ocean and Lake Chad by means of the many rivers, the Niger Delta is a diverse ecosystem of marine organisms recognized as a prime source of aquatic food production (Awosika et al 2001) $)^{5}$.

As a result of decades of overextended petroleum and natural gas exploration and drilling, the lack of foresight to strategically extract these natural resources with minimal impact on the environment, and the primary and collateral pollution associated with these activities has had an adverse impact on coastal and oceanic inhabitants in jeopardy of being eradicated (Argo 2001) ( $^{3}$. Occurrences of the flaring of natural gas and sanitary sewage overflow/ run-off are two of the many factors that contribute to the degradation of the surrounding environment, and increase pollutants contaminating the air and water for residents of the Niger Delta region.

The Niger Delta is located in the southern area of the southern region of Nigeria (Aghalino 2000a, b) ${ }^{1,2}$ and is surrounded by towns and villages of Escravos, Ekpan, and Batan with fishing and farming as the prime industries that support the regional economy (Kamalu and Wokocha 2010) ${ }^{15}$

The magnitude of the oil exploration industry in the Niger Delta, and the subsequent environmental damage and pollution that is associated with it have impacted the way of life and economies of the local inhabitants who earn an income by way of fishing or agricultural farming. But the effects of natural gas flaring and petroleum spillages have tainted the fish supply with toxins as well as the fruits and vegetables that are harvested as well as taking a toll on the health and well-being of the residents too (Ashton et al. $1999)^{4}$. As the production of petroleum takes precedence over the interests of the local residents, their rights towards the alternatives of being gainfully employed in other sectors 
of the economy have been largely ignored. The exploration of petroleum comes with a price to be paid, and that price is the severe and detrimental effects on the environment, which is viewed as a source towards fostering climate change which within the past decade garnered a lot of attention (Vatn $2005)^{23}$, though the failure to respect property ownership rights can amount to problematic conflicts and subsequent losses (Awosika et al. 2001).

The petroleum industry has actually come under attack in a physical sense from local residents who claim they are yet to realize any compensation for seizure of their land and loss of income and livelihood, with damage to petroleum industry infrastructure. In some instances, the petroleum industry has engaged in isolated combat warfare against local residents with the taking of hostages to further emphasize their claims for compensation (Dibia 2011) $)^{8}$. A systematic plan has to be devised with a framework that ensures that the residents of the Niger Delta will be compensated for their loss of income and livelihood and not be subjected to unlawful violent tactics by the petroleum corporations. A possible solution towards sufficient compensation would be employment within the petroleum industry, unfortunately though, the education and skills of the local resident is insufficient as well as instituting standard, regulated policies and procedures to minimize impact on the communities (Kamalu and Wokocha 2010) ${ }^{15}$.

\subsection{Understanding Gas Flaring}

Onshore and offshore wells both conduct the procedure of flaring of natural gas (Farina $2010^{11}$, GGFR 2002 ${ }^{12}$ ); with the intent of facilitating the reduction of pressure in the well and viewed by some as a safety precaution, but in most instances is conducted as a means of disposing excess natural gas, as illustrated in Figure 1 below. Flaring of natural gas in Nigeria adds approximately $1 \%$ to the worldwide $\mathrm{CO}_{2}$ emissions which poses extensive issues for the environment (World bank, 2010) ${ }^{24}$, and is viewed as a pathway to issues associated with absence of consumer goods, cultural and ethnic perceptions towards flaring as waste and insufficient opportunity for economic benefit (World bank, 2010) ${ }^{24}$.

Over the last two decades, the quantity of natural gas that has been flared has remained at a consistent rate of $100 \mathrm{bcm} /$ year with less than 15 countries accounting for nearly $80 \%$ of the volume discharged into the atmosphere, contaminating the environment and a needless exhaustion of valued natural resources (Svalheim 2005) ${ }^{22}$. Collaborative efforts amongst governments and the petroleum industry to curb or eliminate natural gas flaring include the Kyoto Protocol, The Vietnam Rang Dong Project and efforts of the World Bank in conjunction with the Norwegian government (World Bank 2010) ${ }^{24}$.

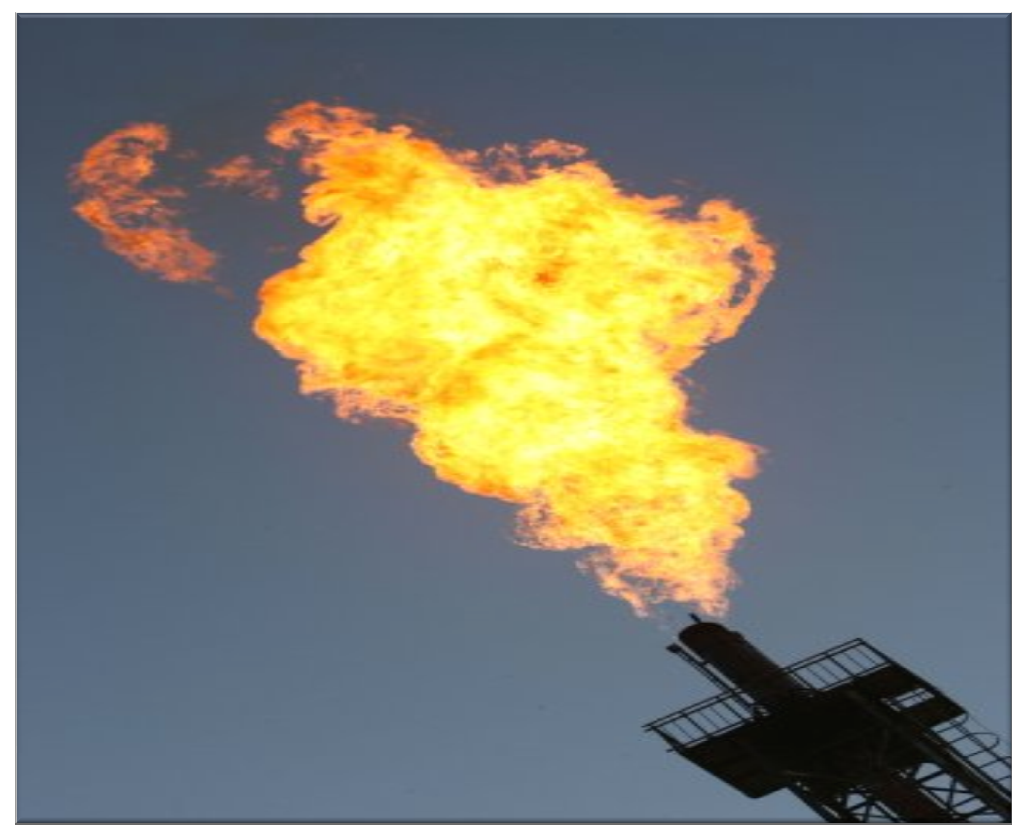

Figure 1. Sample Picture of a Gas Flaring Activity (The World Bank 2011) ${ }^{25}$.

\subsection{Statement of the Problem}

Many problems have become prevalent over the last several decades within the Niger Delta region as a result of excessive of flaring Natural Gas, such as:

- Environmental Damage

- Economic Strife and

- Socio-Ecological Issues.

\subsection{Objectives}

The objectives of this research are as follows:

1. Examine contemporary information concerning gas flaring in Nigeria.

2. Assess the economic and socio-political factors behind gas flaring in Nigeria.

3. Investigate probable economic prospects from the 
elimination of gas flaring in Nigeria.

4. Propose resolution towards developing a sustainable gas industry in Nigeria.

\subsection{Significance of the Project}

With petroleum's inability to be considered a clean burning fuel as a result of the amount of toxins and hazardous compounds that it releases into the atmosphere, it is no longer a viable source of energy, and instills economic distress on individuals and businesses (Davies 2001) ${ }^{7}$. Hence, the quest for other sources of energy which is cost affordable, clean and economic friendly makes natural gas seem as a natural alternative to fuel our residences, businesses, and transportation needs over the long term (Natural Gas 2011) ${ }^{18}$.

The use of natural gas as an alternative to petroleum or fossil fuels offers an array of economic benefits. In comparison to petroleum, natural gas is lower in terms of cost to produce; and burns with negligible amounts of gas emissions (Madueme 2010) ${ }^{16,17}$ and despite these facts, Nigeria continues to flare approximately $80 \%$ of its annually produced natural gas inflicting health issues upon individuals and damaging the environment. Therefore, this study aims to concentrate on the economic impacts of gas flaring in Nigeria, and also the abilities of the Nigerian gas industry in bringing about viable development in the country.

\section{Methodology}

\section{Research Questions}

The questions posed for this research were developed from the framework of the research with the aim of determining the socio-economic and environmental impacts resulting from gas flaring on the populace of the Niger Delta region. The research questions are presented as follows:

1. What is the availability of literature relevant to natural gas flaring in Nigeria?

2. What are the environmental, economic and political impacts of gas flaring in Nigeria?

3. What are the economic prospects in relation to the development of a proper gas plan in Nigeria?

4. What are the opportunities for developing extensive infrastructure for natural gas in Nigeria?

Table 1. Research Methods, Analysis and Selection.

\begin{tabular}{|c|c|c|}
\hline Technique & Advantages & Disadvantages \\
\hline Interview & $\begin{array}{l}\text { - Issues associated with the subject are addressed. } \\
\text { - No future relationship between the interviewer and the interviewee } \\
\text { - It gives the interviewer the opportunity to improve the research by } \\
\text { asking other questions that are relevant to the research }\end{array}$ & $\begin{array}{l}\text { - There may be bias due to interviewer not understanding } \\
\text { the interviewee } \\
\text { - Conducting interviews is costly as it requires relocation } \\
\text { - Difficult in recalling interviewee statements }\end{array}$ \\
\hline Questionnaires & $\begin{array}{l}\text { - Questionnaires are inexpensive method } \\
\text { - It can be completed confidentially } \\
\text { - Many responses can be made before analysis } \\
\text { - Easy to compare and assess }\end{array}$ & $\begin{array}{l}\text { - High probability of responder bias } \\
\text { - Low response rate } \\
\text { - Data received not relevant to questions } \\
\text { - Feedback is useless }\end{array}$ \\
\hline Focus groups & $\begin{array}{l}\text { - High rate of dependability } \\
\text { - Preferred means of data generation } \\
\text { - Means of gathering major and detailed information without bias } \\
\text { - Spans broad range of interest }\end{array}$ & $\begin{array}{l}\text { - Problems assessing collected data } \\
\text { - Mandates presence of trained facilitator prior to data } \\
\text { being generated } \\
\text { - Scheduling difficulties to accommodate everyone }\end{array}$ \\
\hline Observations & $\begin{array}{l}\text { - Monitoring events as they occur } \\
\text { - Create accurate data and information }\end{array}$ & - Data collected may not match the research topic \\
\hline Case studies & $\begin{array}{l}\text { - Offers adequate data methodology and results for project } \\
\text { - High rate of dependability for data collection }\end{array}$ & $\begin{array}{l}\text { - Difficulty in acquiring data } \\
\text { - Analysis of collected data is time consuming }\end{array}$ \\
\hline
\end{tabular}

\section{The Process of Data Collection}

To conduct this research in an unbiased, independent manner, a research statement was drafted in detail explaining the scope of the research, its purpose and the objectives that were to be met. A consent form was sent to all relevant government agencies of Nigeria and petroleum organizations that either is active or having pending operations with regard to petroleum production. Questionnaires (see Appendix) were distributed to verified residents of pre-selected towns and villages that are in near proximity to petroleum production wells. A large sampling of residents was necessary to obtain a true representative view.

100 individuals were selected to receive a questionnaire with their responses recorded electronically or in the presence of a research poll representative. The questionnaires were issued to individuals explaining the purpose of the research along with the assurance that any personal information recorded would remain confidential.

The critical need for the research of this project necessitated a personal trip to the Niger Delta region to see firsthand the existing conditions that may be attributed to natural gas flaring. The visit insured verified distribution of the questionnaires and allowed for the potential respondent to be personally qualified to participate in the research. With a personal visit in lieu of having others administer the questionnaire, it insured a timely response by all 100 individuals, secure collection of all recorded data and completed within the parameters of the original research statement.

A percentage of questionnaires were distributed to the petroleum organizations by means of email. When potential respondents did not submit a response as it approached the deadline, this researcher dispatched made an unannounced visit to inquire as to the status of their completion. The researcher took the opportunity to speak to willing officials 
and staff members as to gas flaring activities and the eventual phasing out of such practices in accordance with government mandates. Critical information provided by those interviewed served as the foundation for the analyzing of attained data.

To support the assessment and analysis of data received; this researcher reviewed electronically retrievable literature and databases relevant to natural gas flaring. Examination was made regarding the social, economic and environmental impacts annually on the inhabitants of the Niger Delta region and the Nigerian government as a result of natural gas flaring. Documents such as conference papers, position/opinion papers, government findings, academic journals as well as internal communications of various agencies (like $\mathrm{CBN}$, NNPC and OPEC) and commercially available publications such as newspapers and magazines were reviewed. Information and data accumulated from research was substantial and supported the intent and mission of this study, and states that type of method utilized for the collection of data clarifies between effects arising from independent variables and those effects that are induced by reactive measurements.

The populace of the Niger Delta region of Nigeria was the focus or 'target' of the research conducted due to its association with natural gas flaring from petroleum exploration and production. Of the 36 states that make up the nation of Nigeria, 9 states are situated in the region referred to as the Niger Delta region. Geodynamics of the Niger Delta region are consistently similar with extensive depositories of petroleum and natural gas throughout Nigeria, though the quality and amounts verified in the Niger Delta region may differ as a result of formation processes. A sample from two or more locations in the Niger Delta will yield the same result as any samples selected from the remaining states. This is due to the fact that the majority of samples is exposed to and suffers from similar social, economic and environment threats because of the uncontested, unregulated flaring, petroleum exploration and production.

\subsection{Research Limitation}

- The accessibility to gas flaring information relevant to petroleum organizations operating in the Niger Delta region is non-existent.
- Illiteracy amongst the populaces of the Niger Delta. This proved the completion of the questionnaires difficult, necessitating personal assistance to assist in their completion.

- The response rate of questionnaires distributed via email was very low. These may be due to lack of access to the Internet or an association with the unwillingness of the petroleum organizations to return their responses.

- The importance of the research had to be emphasized to the staff of the petroleum organizations and the populaces of the Niger Delta who expressed concerns about maintaining confidentiality

- The research was time and labor intensive.

\subsection{Results and Discussion}

Chapter 4 presents the analysis and results stemming from the questionnaire survey collected from three states; Eket of Akwa Ibom, Ogba Land of Rivers state and Imiringi of Bayelsa so as to determine the socio-economic and environmental impact of natural gas flaring on the people that reside in the Niger Delta region. A pie chart is also used to demonstrate the responses received from those returning completed questionnaires.

100 questionnaires were distributed to individuals, with 90 returned fully completed and $22.2 \%$ of the individual respondents were female and $77.8 \%$ were male. Furthermore, the result shows that the questionnaire grouped respondents' classes as:

Age

- $19-29(47.8 \%)$

- $30-39(26.7 \%)$

- $40-49(21.1 \%)$

- $50+(4.4 \%)$

Education

- WASSCE/GCE (36.7\%)

- OND (31.1\%)

- $\mathrm{BSc} / \mathrm{HND}(27.8 \%)$

- $\mathrm{PhD} \& \mathrm{Msc}(4.4 \%)$

Residency

- Niger Delta region (93.3\%)

- Outside of Niger Delta (6.7\%)

Responses

Table 2. States where the interview was conducted

\begin{tabular}{llll}
\hline Names Of States & Names Of villages/Local govt & $\begin{array}{l}\text { Number of questionnaires } \\
\text { distributed }\end{array}$ & $\begin{array}{l}\text { Number of questionnaires } \\
\text { collected }\end{array}$ \\
\hline 1.Akwa Ibom & Eket & $30 \%$ & $29 \%$ \\
2.Rivers & Ogba land & $25 \%$ & $25 \%$ \\
3.Bayelsa & Imiringi & $25 \%$ & $24 \%$ \\
4.Federal Ministry Of Environment & & $10 \%$ & $7 \%$ \\
5.Department Of Petroleum Resource & & $5 \%$ & $2 \%$ \\
6.NNPC & & $5 \%$ & $3 \%$ \\
\hline
\end{tabular}

The above table presents the number of questionnaires distributed and those collected in percentage, $29 \%$ out of $30 \%$ of the respondent are people of AkwaI bom, $25 \%$ out of $25 \%$ are people of rivers, $24 \%$ out of 25 are people of
Bayelsa, $7 \%$ out of $10 \%$ are staff of the Federal ministry of environment, $2 \%$ out of $5 \%$ are staff of the Department of Petroleum Resource and $3 \%$ out of $5 \%$ are staff of the NNPC. 


\section{Does gas flaring affect the social life, economy and evnironment of the Niger Delta?}

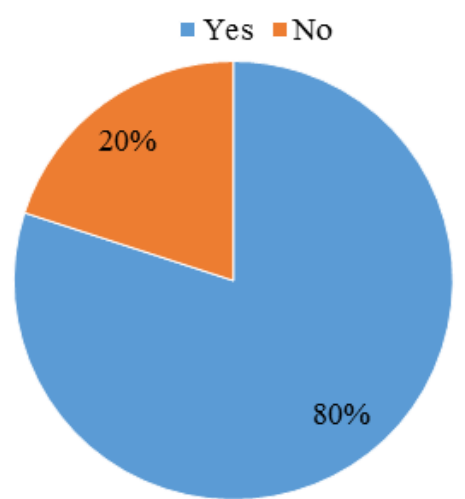

Figure 2. The socio-economic and environmental impacts of gas flaring in the Niger Delta.

$80.0 \%$ of the questionnaire respondents believe that natural gas flaring did contribute to social and economic threats, while other $20.0 \%$ said it was not an issue. The Niger Delta region is agrarian in nature that sustains the local populace by means of fishing and agricultural farming. The harvests from bother industries are sold in local marketplaces. It is widely believed and documented that flaring of natural gas releases hazardous chemical and toxic compounds into the atmosphere, which by means of acid rains percolate into the soils and eventually is absorbed to the rooted fruits and vegetables. These toxic materials also poison waterways and estuaries killing untold amounts of marine life, which serves as a means of support for many residents as fishermen. Looking at the results of the respondents, it can be deduced that $80.0 \%$ agree wholeheartedly that under production of crops which denies them the opportunity to sell their goods, which stymied local economy's growth is directly correlated to natural gas flaring in the local area.

A review of literature during investigation revealed that discharges of nitrous and sulfur oxides along with atmospheric conditions are likely to induce acid rain. It causes agricultural solids to become acidic; this destroys seeds and rooted vegetables and fruits, It is just as it is devastating to marine life. It is believed that climate change can be attributed to exorbitant quantities of methane and carbon dioxide in the atmosphere. As natural gas flaring continues, the production of methane gas along with carbon dioxide accumulates in such massive amounts that it has a devastating impact and in some instances initiates changes in weather patterns that causes drought, coastal erosion, desertification and flooding. Flooding is just as powerful a force as drought is in the eradication of crops, which impacts the Niger Delta's economy. This confirms the findings of Ishione (2004) ${ }^{14}$, which concluded that acid rains, climatic change and temperature elevations have impacts on the economy of the Niger Delta region.

As the natural gas flaring continues to disrupt the economy of the Niger Delta, social disequilibrium has had an impact on social matters of concern, such as; poverty, hunger and more seriously, violence. Community leaders have reached out for assistance from petroleum organizations for assistance to offset the hardships endured as a result of the natural gas flaring. The petroleum organizations are, in some instances slow to respond in a timely manner with relief. Temperaments in the community run rampant when delays are perceived as stalling and avoidance tactics by the petroleum organizations. Abductions, social unrest, rioting and criminal activity occur and more often than not petroleum companies collaborate with the government to forcefully eliminate the demands of the communities that possess the oil.

Seeking infrastructure improvements from the Nigerian government and petroleum organizations, the populace of the Niger Delta has come to the realization that constitutes a political bloc, with some clout in government regulation and legislation. Specific individuals are chosen to act as liaisons between the Nigerian government, the petroleum organizations and for community affairs. These individuals (now in a different social capacity) have increased earnings and in a different social standing that the community represents. This again presents issues of class differentiation and issues pitting the petroleum organizations against local communities. Sonibare $(2006)^{21}$ suggests that community interaction with political forces resulting from petroleum issues are corrupt and does not serve the community in a beneficial way.

Approximately 45,800 gigawatts of heat is released into the atmosphere on a daily basis as a result of gas flaring in Nigeria. According to the World Bank, it would satisfy, approximately $25.0 \%$ of the energy demands of the United Kingdom. If the Nigerian government would enforce strict regulations on gas flaring, the government will generate about $\$ 2.4$ billion in revenue every year, and also be able to provide a cleaner and sustainable environment. Moreover, employment opportunities will be provided to the populaces of the region

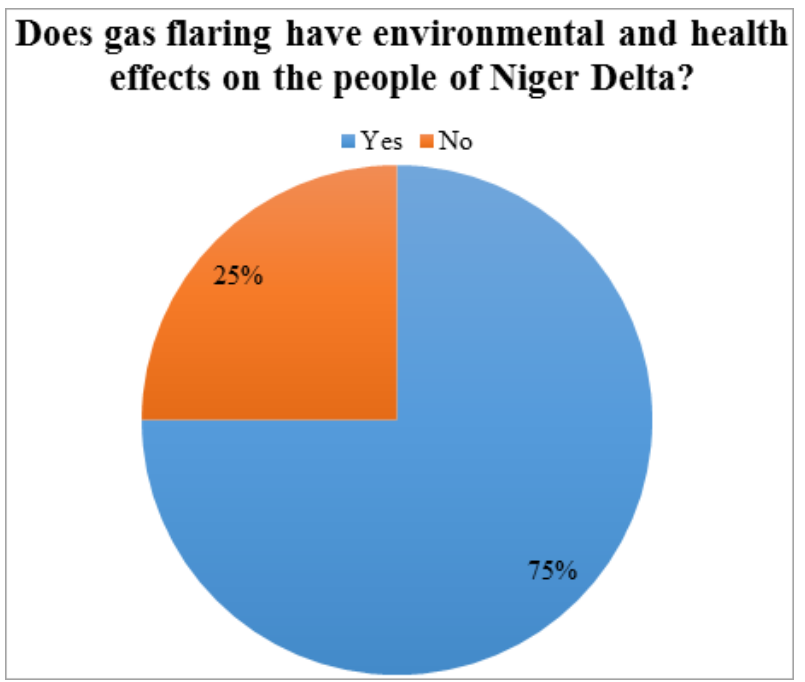

Figure 3. Environmental and Health Effects of Gas Flaring.

$75.0 \%$ of the respondents agree that consequence to an 
individual's health and surrounding environment can occur as a result of Niger Delta natural gas flaring with the remaining $25.0 \%$ seeing no consequence at all. The toxic compounds released into the atmosphere have been shown to cause devastating damage to skin cells, onset of different types of cancers, blood disorders, bronchitis, types of anemia in the communities in proximity to the flaring discharges into the atmosphere. These discharges are comprised of toxic compounds and elements, such as Benzene and enter the food chain. Adverse health conditions substantially reduce one's life expectancy. This makes the life expectancy of the Niger Delta people to be no more than 40 years while in the rest of the country life expectancy is approximately 45 years. Hence a decrease in greenhouse gas emission benefits all human health (Ishione 2004) ${ }^{14}$. In comparison to costs associated with flaring of natural gas, the cost to capture associate gas is 4 times greater (ESMAP 2001) ${ }^{9}$. As a result, petroleum organizations flare the gas. The deposits discharged from the gas have drastic impacts on the environment (e.g. climate change). As noted in fig. $3,75 \%$ of the sampling respondents agree that gas flaring impacts the environment since it releases hazardous and toxic substances like methane, carbon monoxide and sulfur dioxide (Ezzati and Karmmen 2002) ${ }^{10}$. These substances hinder environmental conservation by causing change in climate, flooding and erosion of the shoreline (Ishione 2004) ${ }^{14}$.

\section{Does gas flaring affect the vegetation and agricultural activities in the Niger Delta?}

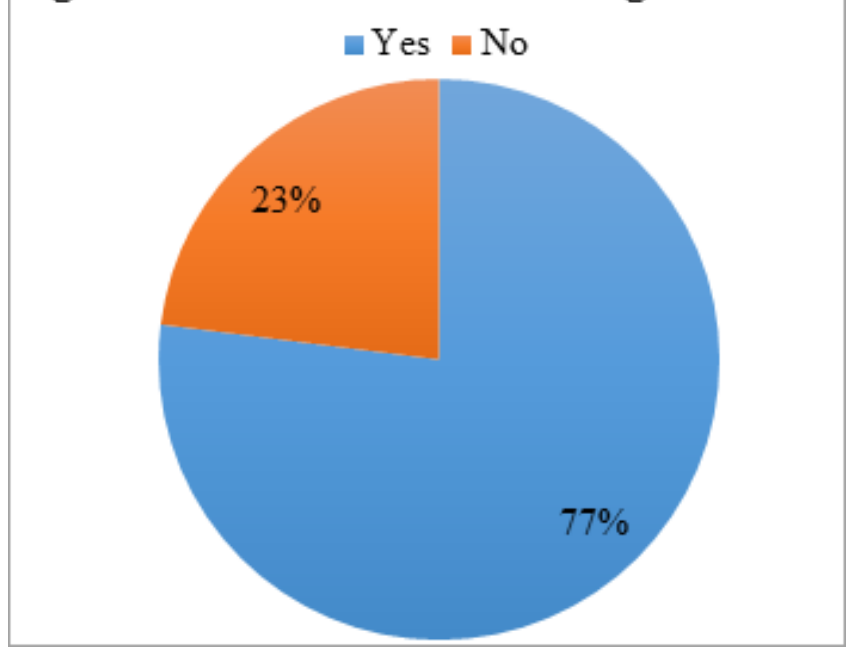

Figure 4. The effect of gas flaring on agriculture and vegetation.

Climate change resulting from gas flaring can cause severe erosion of coastal shorelines and flooding in the Niger Delta region which are considered to be lowlands; the devastating climatic events destroy agricultural crops and lead to outbreak of diseases. $77.0 \%$ of the questionnaire respondents agree that natural gas flaring contributes to destruction of agricultural crops by means of drought, flooding and drastic variations in temperatures.

Acidic soil as a result from acid rain serves to only inhibit the development and growth of agricultural crops and the industry itself. Acidity of the soil depletes essential nutrients need, and can be attributed to the flaring of natural gas, as confirmed by investigative research conducted by Ishione $(2004)^{14}$.

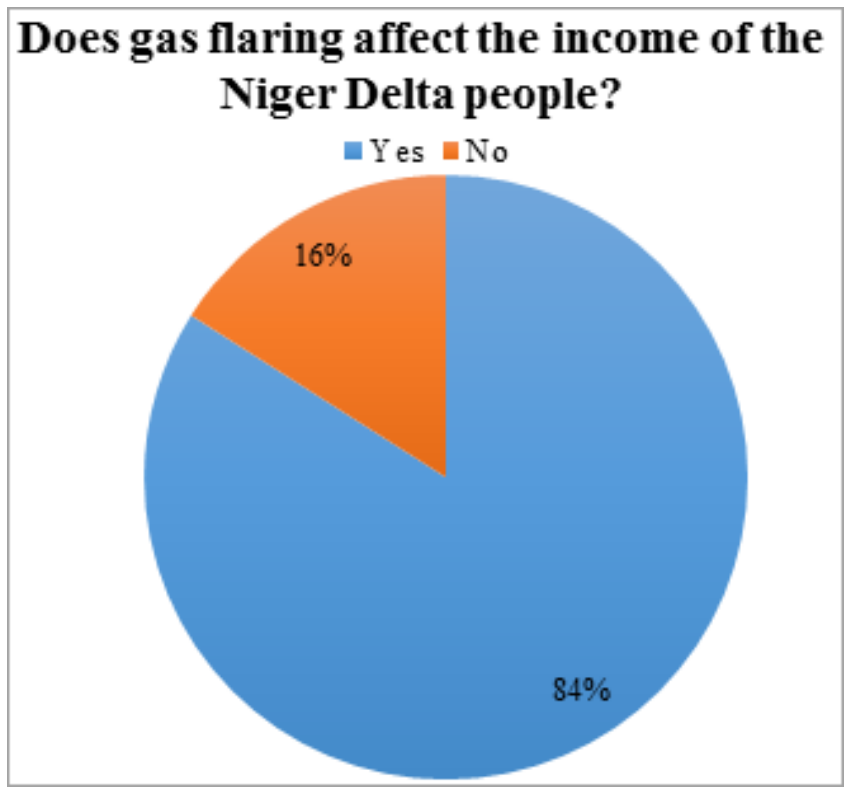

Figure 5. The effect of gas flaring on income generation.

Results from the questionnaire indicate that $84.0 \%$ of the respondents believe that flaring of natural gas has a direct impact on the income of the population of the Niger Delta region, while the remaining $16.0 \%$ indicate that gas flaring felt no impact at all. This amounts to approximately 1 out of 5 respondents stating that natural gas flaring has an impact on the industries they are employed in and has a direct correlation to their annual incomes. A majority of the population of the Niger Delta region are farmers or workers in the agricultural sector in addition to fisherman. Many of the respondents do not understand the scientific or technical reason why their crops and fishing hauls are being destroyed or depleted but they do know that prior to the installation of petroleum rigs and extensive petroleum exploration, that they harvested bumper agricultural crops and netted tons of fish that were sold in local and exported market places for substantial monetary gain.

Of the income generated by the local population, much of it is spent on medical treatments to treat medical conditions, ailments and chronic diseases resulting from the flaring of natural gas. In some instances, farmers pool some of their incomes to initiate erosion control, vegetation diseases, and flaring eradication to protect their agricultural harvests and incomes. These 'investments' by farmers and fishermen to protect the incomes severely decrease the available income to feed their families, which supports the conclusions of the World Bank (2011) ${ }^{25}$ that the series of events that arise from gas flaring purposely reduce the income of the Niger Delta inhabitants. 


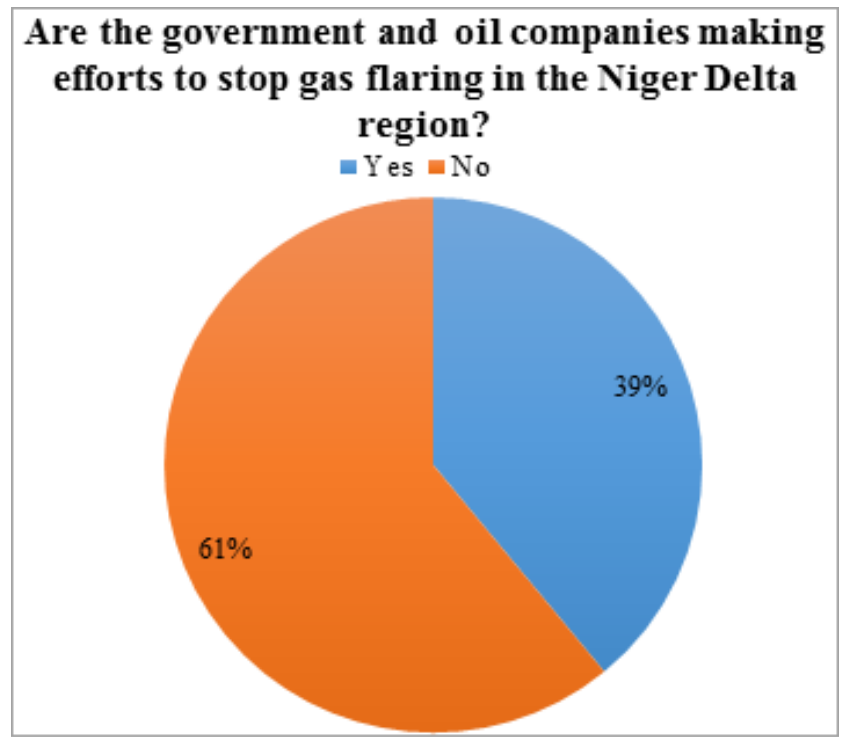

Figure 6. Government and Oil company efforts to eradicate gas flaring.

$39.0 \%$ of the respondents to the questionnaire believe that the Nigerian government along with the petroleum organizations have a credible plan established to eliminate natural gas flaring, while the remaining $61.0 \%$ believe that no such plan exists. Further investigation and analysis of the respondents' answers indicate that the majority of the $39.0 \%$ that believe that petroleum organization and the government have plans to eliminate natural gas flaring are in fact workers for the petroleum organizations and the government. This leads to the belief that the responses are biases, with the fact that the other $61.0 \%$ of respondents are residents of the Niger Delta with no affiliation or allegiance with the government or petroleum organizations. The establishment of the national Gas Master plan in 2008 was to focus on maximizing the conversion of waste gas into a beneficial product that can be monetarily capitalized on. Creation of measures, standards, regulations and legislation are fantastic, but enforcement and monitoring by the general public is often difficult if not nonexistent, due to the fact that the residents lack discretionary income to purchase radio, televisions or computers to stay in touch with activities that are of importance to them, such as natural gas flaring. Chevron has initiated the capture of associated gas while other petroleum organizations have started designing development of new platforms that will help them comply with the government's regulations to eliminate gas flaring in the country by the designated time.

A part of the questionnaire ascertains the opinion of respondents toward eliminating the flaring of natural gas in Nigeria. $72.0 \%$ of the respondents indicated that established measures, standards, regulations and legislation should be examined and consideration given to updating them and eliminating unnecessary one. $28.0 \%$ of the respondents believe that the already established measures, standards, regulations and legislation are sufficient. These $28.0 \%$ of respondents, it should be noted are employed by the government and petroleum organization.

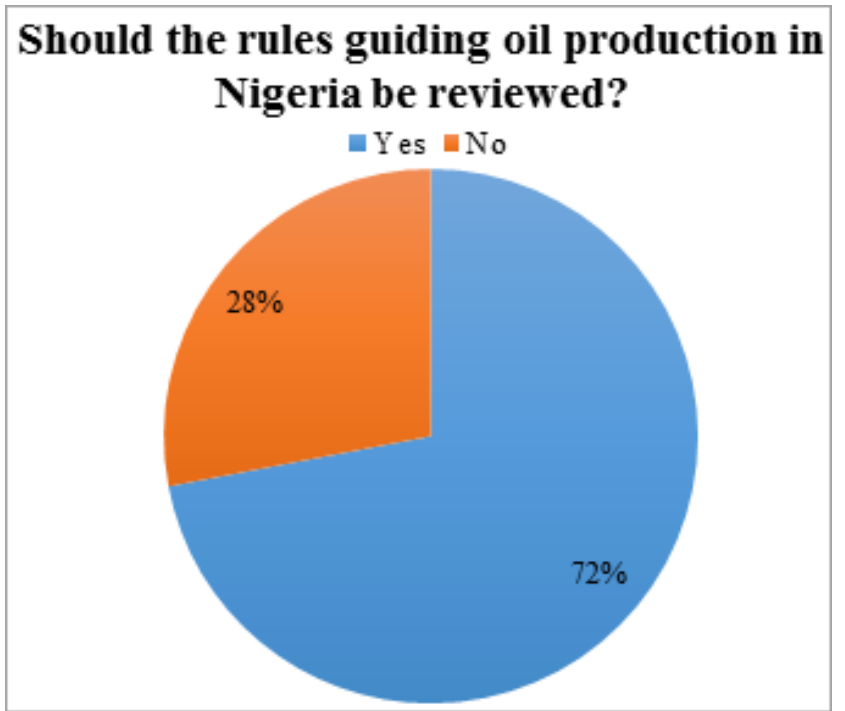

Figure 7. The need for review of laws guiding oil production in Nigeria.

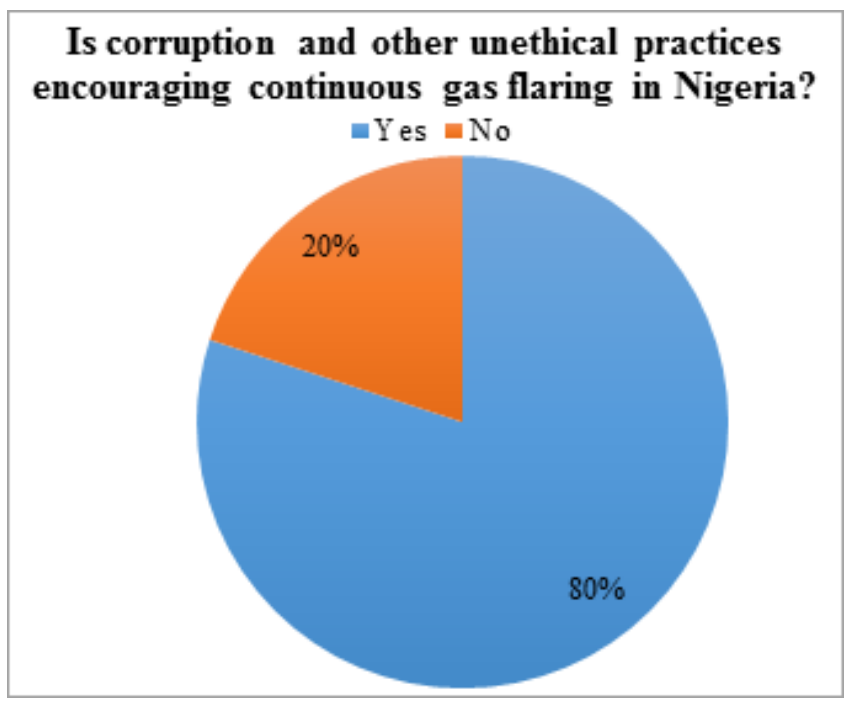

Figure 8. The effect of corruption and unethical practices on gas flaring.

$80.0 \%$ of the respondents agree that corruption plays a vital role in the everlasting practice of gas flaring in Nigeria. The remaining $20.0 \%$ disagree with that claim. There are many hidden agendas behind the continuous gas flaring in the Niger delta, and this keeps the Niger Delta people in suspense.

The majority of the people that agree that corruption and ethical issues are some of the major driving forces of gas flaring in Nigeria are the civil servants and the populaces of the Niger Delta. But the remaining 20.0\% that disagree with the argument are mostly the workers of the multinational oil companies. The survey was crafted to uncover the prime reason why flaring of natural gas in Nigeria continues in direct violation of measures, standards, regulations and legislation. Meanwhile the $20.0 \%$ of the respondents believe that the measures, standards, regulations and legislation are being enforced in an honest and legal manner. There is much political influence in the natural gas and petroleum industries in Nigeria and have the ability to influence decision makers 
in government to achieve whatever is necessary, such as continuously extending the government imposed deadline for the cessation and elimination of natural gas flaring in Nigeria (Ishione 2004) ${ }^{14}$.

\section{Interview Result Analysis}

Members of the staff of senior management at The Federal Ministries of Environment, Petroleum and Department for Petroleum Resource were questioned in a follow up to the questionnaires they return uncompleted. The intent was to uncover answers that were not provided. 7 senior management staffers and 2 community leaders were interviewed and as an incentive, were offered paid positions in association with the implementation of the Gas Master plan that was adopted by the Federal government in 2008.

\subsection{What are the Economic Prospects in Relation to the Development of a Proper Gas Plan in Nigeria}

The analysis of the interviewees responses indicate that the government has proposed a Gas master plan, which is a policy used to improve the local demand of natural gas, and also develop better facilities for gas production. This policy (if implemented) will develop the weak sectors of the Nigerian economy.

The primary thrust of the Gas Master plan is to increase and enhance the demand for natural gas in Nigeria. Key points of the master plan include;

- Export of Natural Gas

- Increase Domestic demand

- Economic growth other than business sectors

The promising future of the elimination of natural gas flaring is viewed with the prospect of financial gain, which will be utilized in a myriad of sectors and purposes, such as power generation and distribution, petrochemical industry, fertilizer production throughout the country. Economic prosperity is anticipated with employment opportunities multiplying throughout the country.

With the prospering economy, Nigeria will benefit from an increase in the foreign earning exchange, which will enable industrial, and agricultural diversification to support the country instead of being continuously dependent on the sale of petroleum exclusively. Attempts will be made to legislate government transparency regarding the Gas master plan. Other critical information disclosed by interviewees include

- Increase in revenue allocated for treating diseases arising from gas flaring

- Cleaner and sustainable environment

- Improved agricultural sector

\subsection{What are the Prospects for Developing Extensive Infrastructure for Natural Gas in Nigeria}

Opinions of the interviewees reflect the prospects and hopes for the development of thriving natural gas industry in Nigeria as a result of the stringent implementation and enforcement of the National Gas Master plan. As result of the implementation and enforcement, the interviewees foresee promising economic development, growth of the country and enrichment or betterment of the lives of the Nigerian citizens. Due to continuous exploration and production of petroleum, fields are becoming increasingly depleted, natural gas is an inexpensive energy source alternative. This allows for the development of new and advanced technologies and contemporary engineering concepts for this burgeoning industry in Nigeria.

Regulatory complexities and commercial legislative polices of the government are instrumental in the development and expansion of the natural gas industry and is in accordance with observation made by Aghalino $(2009)^{2}$, which is concerned with the critical analysis of the viability of projects, the integrity of engineering designs and concepts and other factors that should be considered before the commencement of the production of natural gas in Nigeria. Odumugbo $(2011)^{19}$ asserts that if adequate attention is paid to those factors, the Nigerian economy shall experience extensive economic opportunities.

- Without an established and self-sustaining power grid in Nigeria, many entrepreneurs are relegated to providing necessary power to operate their business. The associate cost of energy production is inherently passed on to the consumer. With a revamped petroleum process, natural gas is used for power generation instead of being flared into the atmosphere. This is in concert with positions taken by Aghalino (2009) ${ }^{2}$, and Odumugbo (2011) ${ }^{19}$ that nation can reach a level of consistent power for domestic and industrial uses via the conversion of flared gas. According to Ishione (2004) ${ }^{14}$, this can only be attained by aggressive construction of power transmission and distribution and reception facilities.

- Large-scale production of natural gas must be preceded with an established infrastructure for the containment and storage of natural gas, countrywide. Demand for gas will increase due to its inexpensiveness and will be utilized as a new source of energy in regions that were strictly dependent on petroleum. New modes of delivery will facilitate the expansion of the use of natural gas and create new marketplaces for its use. Foreign and domestic investment opportunities will become available to maintain existing infrastructure and encourage the conceptual design for the eventual replacement of the current infrastructure with cost effective, technologically advanced infrastructure in projects such as the Nigerian Liquefied Natural Gas Plant in Bonny. These enhancements elevate Nigeria's standing as a contemporary in terms of energy production and allow for fiscal gain through elevated foreign exchange.

- The opinions of the interviewees are in agreement with the inferences of Odumugbo $(2010)^{19}$, which claim that natural gas re-injection restores the pressure of the reservoir and prevents the emission of hazardous and toxic materials into the environment. This provides a cleaner and more sustainable environment (Ayodele 
$1998)^{6}$. Introducing the re-injection process of natural gas to stimulate petroleum will create opportunities of increasing the wells economic life cycle. The opinions of the interviewees is in compliance with the inferences of Odumugbo $(2010)^{19}$, which claims that natural gas reinjection stimulates petroleum reservoirs and spars the environment to be susceptible to toxic compounds, a byproduct gas flaring (Ayodele 1998) ${ }^{6}$.

- Human health and wellbeing along with the environment are the innocent victims of natural gas flaring. Greenhouse gases being emitted into the atmosphere contribute to a continual deterioration and decline of the quality of air, soil and water resources while inflicting horrific diseases and ailments on individuals.

- The populations of the Niger Delta region will be afforded the opportunity to breathe clean air, drink fresh water and be able to harvest edible fruits, vegetables and fish abundantly with concern for marine life being tainted with toxic compound and chemicals, with the development of the gas industry in Nigeria. The quality of health will increase in generations to come and rejuvenate surrounding forests devastated by soil toxicity and acid rains (Opukri and Ibaba 2008) ${ }^{20}$.

- The process of exporting the Natural Gas requires skilled technicians. As the development of the natural gas industries takes to a larger scale, a substantial amount of employment opportunities will be created in the petroleum and natural gas sectors. This employment boom will boost the economy, creating job in other sectors, which is in accordance with the investigation and research of Ayodele (1998) ${ }^{6}$ that the proliferation of the production of natural gas in Nigeria will stimulate employment opportunities for Nigerian citizens.

\section{Conclusions}

With worldwide awareness of the ramifications of climate change and its annihilating wrath of devastation it can wreak upon the environment, it is enough for many to realize that preventive measures are in order. One of those preventive measures is the use of a clean natural resource, such as natural gas.

For nearly 55 years, the petroleum industry in Nigeria wields with as iron first, so to say how procedures with regard to petroleum exploration and production are handled. They believe that flaring of natural gas is an effective means of waste disposal with little regard for the impact it is having on the economic conditions and the personal health of individuals in the Niger Delta. Even though continuous attempts at eradicating natural gas flaring have failed in the past, they did not have political support and message conveyed in manner of reaping the benefits economically and health wise for individuals.

The conclusion of this project can unequivocally state that the economy, environment and populace of the Niger Delta have endured hardship resulting from the unabated flaring of natural gas. The waste by products of gas flaring is a contributing factor towards initiating climate change, which imperils the air, water and food supplies. Air becomes unbreathable leading to illness as well as waterways becoming toxic, thus impacting fisheries, agricultural farmlands and the economy.

This research also ascertains that the Nigerian government and the Niger-Delta populace can experience several environmental, economic and health benefits if gas flaring were to cease, and points out several measures that can be adopted in order to develop a feasible natural gas business in Nigeria.

\section{Recommendation}

1. Strict government legislations on how the gas production projects should be conducted.

2. Regulatory agencies must fulfill their responsibilities and duties of enforcing laws and regulations to cease gas flaring.

3. The government must provide incentives and fiscal policies conducive to large-scale production and demand for gas.

4. Establish research and development of natural gas, initiate workforce-training programs.

5. The escaping natural gas should be captured and reinjected in order to increase the pressure of the reservoir.

6. Good transportation network should be provided

7. Government should impose penalties against firms continuing to engage in gas flaring.

8. The government should allow the gas sectors to undergo deregulation to improve its productivity and technologies.

\section{Appendix}

\section{Questionnaire Sample}

\section{The Impact of Gas Flaring in Nigeria}

The purpose of this study is to investigate the effects of gas flaring in Nigeria. Participation is voluntary, and all the data/information obtained from this study will be anonymous and confidential. Thank you for your time.

Phone no: 07037733282, 08057932171

Email: mustinmama@yahoo.com

\section{Section 1: (Bio Data)}

1. Gender

Male [ ] Female [ ]

2. Age Category
(a) 19-29 [ ] (b) 30-39 [ ]
(c) 40-49 [ ] (d) 50 and Above []

3. Residency

(a) Niger Delta [ ] (b) Other [ ]

(c) State

(d) Local Govt ........

4. Qualification
(a) $\mathrm{PhD} \& \mathrm{MSc}$
(b) $\mathrm{BSc} / \mathrm{HND}$
(c) OND

5. Employer Name 
Specify if: (a) Private [ ] (b) Governmental [ ]

6. Position

\section{Section 2: Assessment}

1. Does gas flaring affect the social life, economy and environment of the Niger Delta?

(a) Yes [ ] (b) No []

2. Does gas flaring have environmental and health effects on the people of Niger Delta?

(a) Yes [ ] (b) No []

3. Does gas flaring affect the vegetation and agricultural activities in the Niger Delta?

(a) Yes [ ] (b) No [ ]

4. Does gas flaring affect the income of the Niger Delta people?

(a) Yes [ ] (b) No [ ]

5. Are the government and oil companies making efforts to stop gas flaring in the Niger Delta region?

(a) Yes [ ] (b) No []

6. Should the rules guiding oil production in Nigeria be reviewed?

(a) Yes [ ] (b) No []

7. Are corruption and other unethical practices encouraging continuous gas flaring in Nigeria?

(a) Yes [ ] (b) No []

\section{References}

[1] Aghalino S. (2000) Petroleum Exploitation and Environmental Degradation in Nigeria. In: HI Jimoh, IP Ifabiyi (Eds.): Contemporary Issues in Environmental Studies. Ilorin: Haytee Press

[2] Aghalino S (2009) Petroleum Exploitation and the Agitation for Compensation by Oil Mineral Producing Communities in Nigeria. Geo-Studies Forum, 1(1, 2): 11-20.

[3] Argo, J (2001) Unhealthy effects of upstream oil and gas flaring [Online], Available from: http://www.sierraclub.ca/national/oil-and-gasexploration/soss-oil-and-gas-flaring.pdf[Accessed: 28.7.2012]

[4] Ashton, N., Arnott, S., and Douglas, O. (1999) The Human Ecosystems of the Niger Delta - An ERA handbook. Lagos: Environmental Rights Action.

[5] Awosika, F., Osuntogun, C., Oyewo, O. and Awobamise, A, (2001) Development and Protection of the Coastal and Marine Environment in Sub sahara Africa: Report of the Nigeria Integrated Problem Analysis

[6] Ayodele, A. (1998) Improving and Sustaining Power (electricity) 'Supply for Socio-economic Development in Nigeria'. Bulhon Publication of CBN 36, 38-58.

[7] Davies, P. (2001) The New Challenge of Natural Gas. Paper presented at "OPEC and the Global Energy Balance: Towards a Sustainable Future", Vienna, September 28, 10-11

[8] Dibia, B. (2011) The Impact of Gas Flaring in Nigeria. Unpublised MSc thesis. Coventry: Coventry University.
[9] ESMAP (2001) African gas Initiative: main report. [Online], Available from: http://www.worldbank.org/html/fpd/energy/ AGI/240-

$01 \% 20$ Africa $\% 20$ Gas\%20Initiative\%20Main\%20Report.pdf[ Accessed: 26.7.2012]

[10] Ezzati, M. and Kammen, D (2002) 'Household energy, indoor air pollution, and health developing countries: knowledge base for effective interventions'. Annual Reviews Energy and Environment 27: 233-270.

[11] Farina, M. F. (2010) Flare Gas Reduction: Recent Global Trends and Policy Considerations. Oak Park: General Energy Company.

[12] GGFR (2002) Report on Consultations with Stakeholders. World Bank Group in collaboration with the Government of Norway [online] Available from: http://www.worldbank.org/ogmc/files/global_gas_flaring_initi ative.pdf[Accessed: 01.08.2012]

[13] Human Development Report (2011) [online] available from: http://hdr.undp.org/en/ [Accessed: 29.7.2012]

[14] Ishione, M (2004) GasFlaring in the Niger Delta: the Potential Benefits of its Reduction on the Local Economy and Environment [Online], Available from: http://nature.berkeley.edu/classes/es196/projects/2004final/Ish one.pdf[Accessed: 24.7.2012]

[15] Kamalu, O.J., and Wokocha, C.C (2010) 'Lan resource Inventory and Ecological Vulnerability; Assessment of Onne Area in Rivers State, Nigeria'. Research Journal of Environmental and Earth Science 3(5) 438-447

[16] Madueme, S (2010) "Economic Analysis of Wastages in the Nigerian Gas Industry". International Journal of Engineering Science and Technology 2(4), 618-624

[17] Madueme S (2010) Gas flaring activities of major oil companies in Nigeria: An economic investigation. InternationalJournal of Engineering and Technology, 2(4): 610-617.

[18] Natural gas (2011) History [online], Available from: http://www.naturalgas.org/overview/history.asp[Accessed: 25.7.2012]

[19] Odumugbo, C (2010) Natural Gas Utilisation in Nigeria: Challenges and Opportunities. Journal of Natural Gas Science and Engineering 2(6) 310-316.

[20] Opukri, O., and Ibaba, S. (2008) "Oil Induced Environmental Degradation and Internal Population Displacement in the Nigeria's Niger Delta".Journal of Sustainable Development in Africa 10 (1), 173-193

[21] Sonibare, A., and Akeredolu, A (2006) "Natural Gas Domestic Market Development for Total Elimination of Routine Flares in Nigeria's Upstream Petroleum Operations". Energy Policy34 (6), 743-753.

[22] Svalheim, S. (2005) Norwegian initiative for responsible, environmentally-friendly gas management, Published by the Norwegian Petroleum Directorate [online] Available from: http://www.npd.no/cgibin/MsmGo.exe?grab id=24\&EXTRA $\mathrm{ARG}=\& \mathrm{CFGNAME}=$ MssFindEN\%2Ecfg\&host_id=42\&page id $=4285184 \&$ query $=$ gas + flaring $\&$ hiword $=$ gas + flaring + [Accessed: 25.7.2012] 
[23] Vatn, A. (2005) Institutions and the Environment. Cheltenham: Edward Elgar Publishing Limited

[24] World Bank (2010) [online], Available from: http://web.worldbank.org/WBSITE/EXTERNAL/TOPICS/EX TSDNET/0,,contentMDK:22679372 menuPK:64885113 pag ePK:7278667 piPK:64911824 theSitePK:5929282,00.html[A ccessed: 25.7.2012]
[25] World Bank 2011, October 2003 [online], Available from: http://go.worldbank.org/ARNU3Z3BR0 [Accessed: 25.7.2012] 